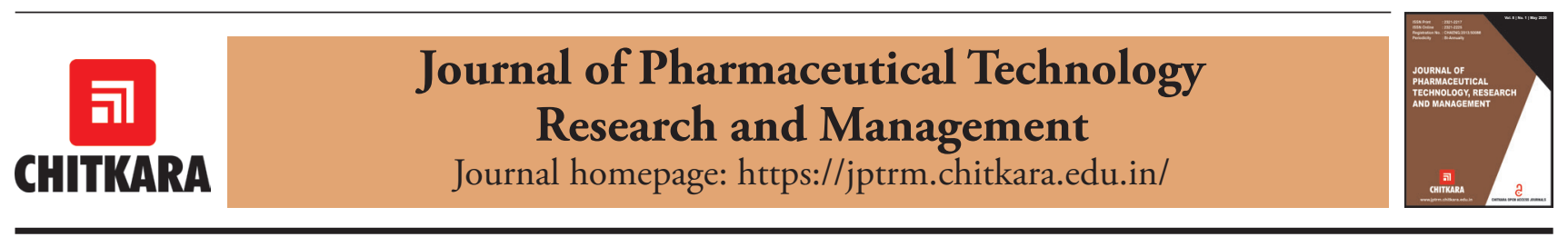

\title{
Antioxidant Potential of Glycyrrhiza Glabra L. Roots: In-Vitro Evidences
}

\author{
Varinder Singh ${ }^{1}$ and Amit Kumar ${ }^{2 *}$ \\ Chitkara College of Pharmacy, Chitkara University, Punjab-140401, India \\ ${ }^{1}$ varinder.9096@chitkara.edu.in \\ 2*amit.k@chitkara.edu.in (Corresponding Author)
}

\section{ARTICLE INFORMATION}

Received: January 03, 2020

Revised: February 11, 2020

Accepted: March 10, 2020

Published Online: May 20, 2020

Keywords:

Glycyrrhiza Glabra, Antioxidant,

Phenolic Compound, Free Radical

\begin{abstract}
Background: The study was aimed to determine the mechanism of antioxidant effects of Glycyrrhiza glabra L. (GG) roots using in-vitro assays.

Methods: The various extracts of GG roots were prepared and evaluated for DPPH scavenging, reducing effects and nitric oxide inhibiting activities. Prepared extracts were screened for the presence of various phytochemicals and quantified on the basis of phytochemical present therein. Results: The results showed that all the prepared extracts contained phenolic compounds. Also, extract showed appreciable antioxidant effects in all three assays employed. However, among prepared extracts, ethylacetate extract was found to have strong free radical inhibition, ferric reducing potential and nitric oxide inhibitory effects. The reason for high antioxidant activity in ethylacetate extract could be attributed to the significant amount of phenol compounds present in it. Conclusion: Evidently, GG's capacity to scavenge free radicals, reducing potential and inhibit nitric oxide contributes to its antioxidant effects and thus, could be a strong candidate for developing antioxidant based drug therapy.
\end{abstract}

the antioxidant effect of GG in different assays has not been systematically investigated. Therefore, the present study is designed to evaluate GG for antioxidant activity using various in-vitro assays.

\section{Material and Methods}

The GG roots were procured from local market of Patiala, Punjab, India. The obtained roots were dried and powdered. The powdered material was extracted by maceration as described in Figure 1. Qualitative tests to identify different compounds in extracts was done as described by Singh et al., (2016). Quantitative estimation of phenol was performed as described by Singh et al., (2016).

\subsection{Free Radical Scavenging Potential}

The radical inhibitory effect of prepared extracts was determined by DPPH assay. The extracts were dissolved in methanol and its $10-70 \mu \mathrm{g} / \mathrm{ml}$ concentrations were prepared. One $\mathrm{ml}$ of each dilution was mixed with $1 \mathrm{ml}$ solution of DPPH. The mixture was kept under incubation for 15 minutes and the absorbance was noted by UV spectrophotometer. Ascorbic acid $(1-20 \mu \mathrm{g} / \mathrm{ml})$ was used as standard drug. The percentage inhibition was calculated as described by Singh et al., (2016). 


\subsection{Reducing Potential}

The reducing potential of prepared extracts was determined in terms of ferric reducing capacity. The extracts were dissolved in methanol and its $10-70 \mu \mathrm{g} / \mathrm{ml}$ concentrations were prepared. Each concentration was allowed to react with potassium ferricyanide in presence of trichloroacetic acid as described by Singh et al., (2016). Ascorbic acid was used as standard drug (Ahmed, Khan \& Saeed, 2015).

\subsection{Nitric Oxide Inhibitory Potential}

The nitric oxide inhibitory effect of prepared extracts $(10-70 \mu \mathrm{g} / \mathrm{ml})$ was determined by Griess reagent as described by Basu \& Hazra, (2006). Ascorbic acid was used as positive control.

\section{Results and Discussion}

Free radicals are very reactive molecules that are formed during interaction of oxygen or nitrogen with certain biomolecules. Based on the capacity of free radicals to accept or donate electron, they are called as oxidant and reductant, respectively. These reactive radicals (oxygen or nitrogen) have capacity to interact with various cellular molecules and shows deleterious effects such as DNA damage, apoptosis, mitochondrial dysfunction etc and thus, play significant role in the progression of various age and non-age related disorders (Liguori et al., 2018; Pizzino et al., 2017). Nitric oxide is released by neurons, macrophages and endothelial cells and causes inflammatory pathways (Lubos, Handy \& Loscalzo, 2008). Therefore, to prevent and manage health disorders, it is necessary to develop drugs that can counteract the action of these energetic radicals.

In the present study, GG roots were tested whether it has free radical scavenging properties using in-vitro assays. In-vitro DPPH, ferric reducing antioxidant potential (FRAP) and nitric oxide inhibitory assays are widely used methods to screen drugs for antioxidant effects. These assays are easy to perform, accurate and give reproducible results. Furthermore, these methods depict the different antioxidant mechanisms. Therefore, these methods are selected in the present study to evaluate radical scavenging, reducing potential and nitric oxide inhibitory effects of GG extracts.

The gradient extraction of GG roots showed varied percentage yield of extracts. Since, methanol extract showed highest percentage yield, it is likely that GG roots contained high content of polar compounds (Table 1). The percentage yield and physical properties of prepared extract are given in Table 1. The phytochemical screening showed the presence of phenols in all the prepared extracts while carbohydrates were found to be present in aqueous extract only. Quantitative analysis of phenols in extracts showed that ethylacetate extract had highest amount (Table 2, Figure 2).

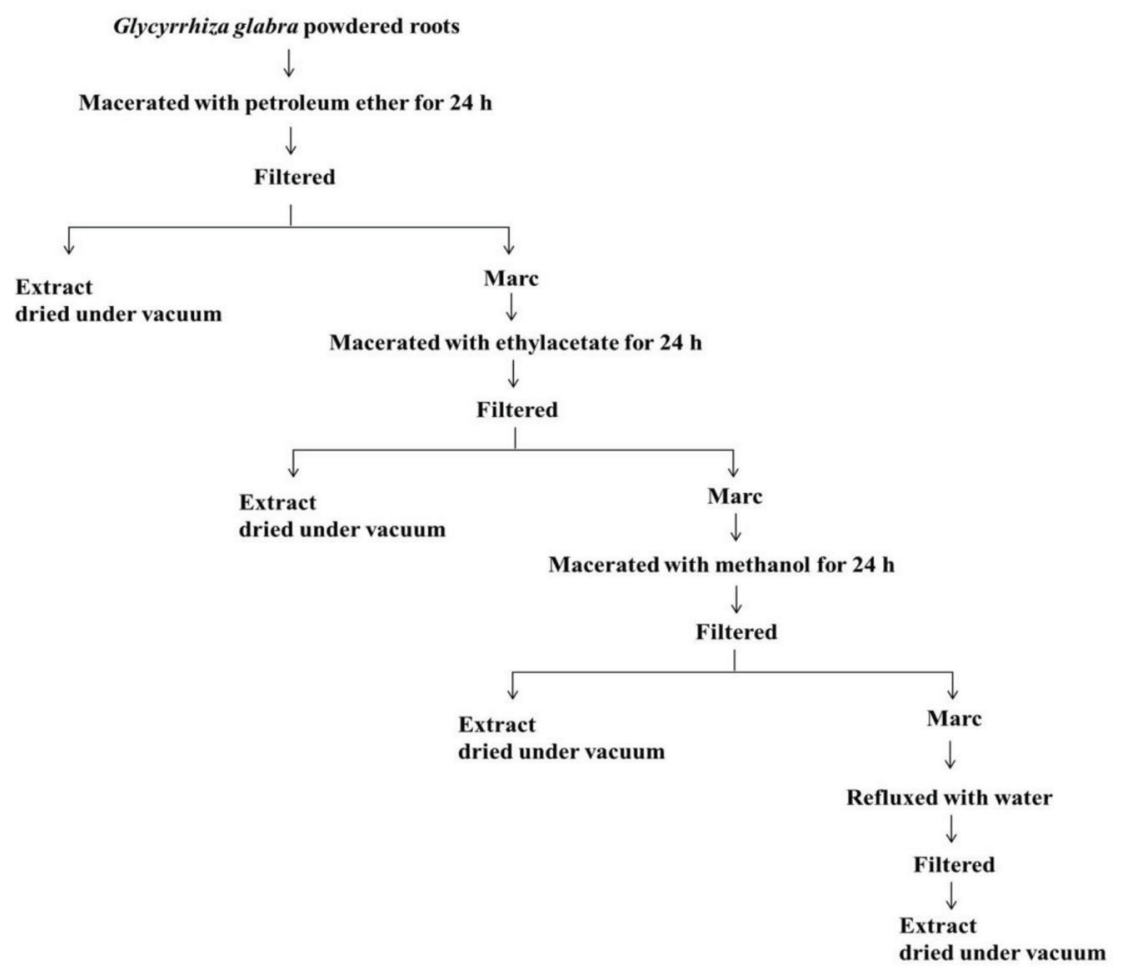

Figure 1: Extraction scheme. 
Table 1: Percentage yield and physical properties of prepared extracts.

\begin{tabular}{|l|l|l|l|}
\hline Extract & Colour & Consistency & $\begin{array}{l}\text { Percentage yield } \\
(\% \mathbf{w} / \mathbf{w}, \text { air dried } \\
\text { material })\end{array}$ \\
\hline $\begin{array}{l}\text { Petroleum } \\
\text { ether }\end{array}$ & $\begin{array}{l}\text { Yellowish } \\
\text { green }\end{array}$ & Semi-solid & 1.02 \\
\hline Ethylacetate & Brown & Semi-solid & 2.76 \\
\hline Methanol & Brown & Semi-solid & 4.28 \\
\hline Aqueous & $\begin{array}{l}\text { Yellowish } \\
\text { brown }\end{array}$ & Semi-solid & 3.11 \\
\hline
\end{tabular}

Table 2: Phytochemical screening and total phenol content of prepared extracts.

\begin{tabular}{|l|l|l|}
\hline Extract & $\begin{array}{l}\text { Phytochemical } \\
\text { screening }\end{array}$ & $\begin{array}{l}\text { Total phenol content } \\
\text { (mg/g of dried extract) }\end{array}$ \\
\hline $\begin{array}{l}\text { Petroleum } \\
\text { ether }\end{array}$ & Steroids, terpenoids & Not determined \\
\hline Ethylacetate & Terpenoids, phenols & 2.4 \\
\hline Methanol & $\begin{array}{l}\text { Phenols, flavonoids, } \\
\text { carbohydrates }\end{array}$ & 1.8 \\
\hline Aqueous & $\begin{array}{l}\text { Phenols, flavonoids, } \\
\text { carbohydrates }\end{array}$ & 1.4 \\
\hline
\end{tabular}

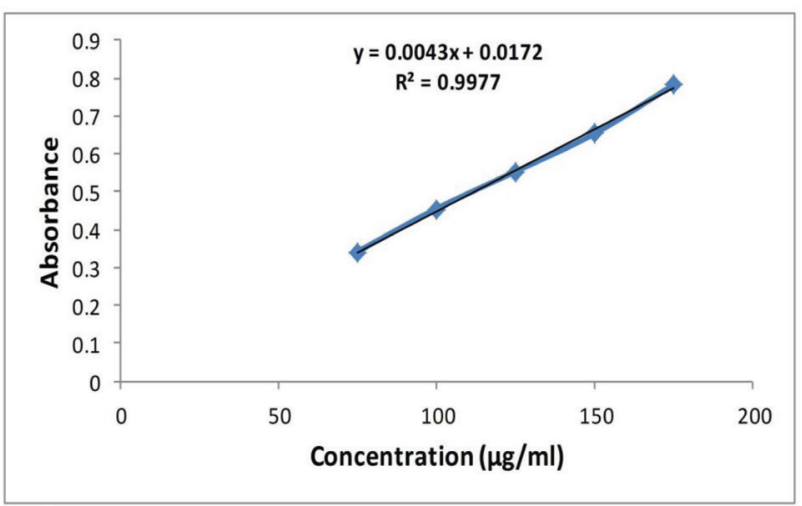

Figure 2:. Standard plot for total phenol content.

In in-vitro antioxidant analysis, all the extracts exhibited antioxidant effects. However, ethylacetate extract showed marked antioxidant potential in all the three methods employed (Figure 3-5).

Phenols are well established antioxidant compounds and are reported to be beneficial in various diseases including, cancer, diabetes, neurodegenerative, kidney, liver, hypertension, cardiovascular disorders (Pandey \& Rizvi, 2009; Dzialo et al., 2016). Keeping in view the beneficial effects of phenols, it is possible that higher phenol content in ethylacetate extract contribute to its antioxidant effects. However, these results warrant further studies including isolation of antioxidant compound and in-vivo investigations.

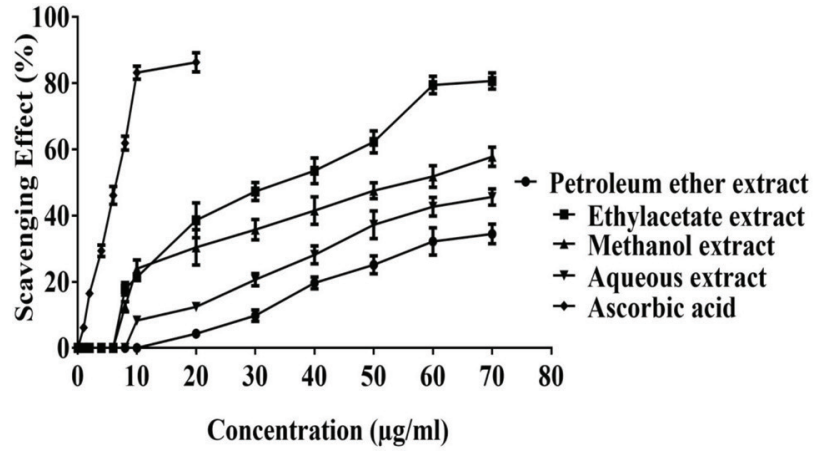

Figure 3: DPPH scavenging effects of extracts.

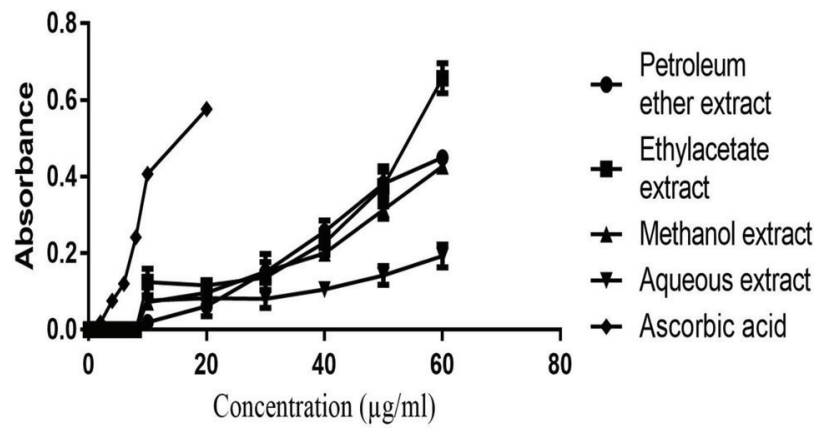

Figure 4: Ferric reducing potential of extracts.

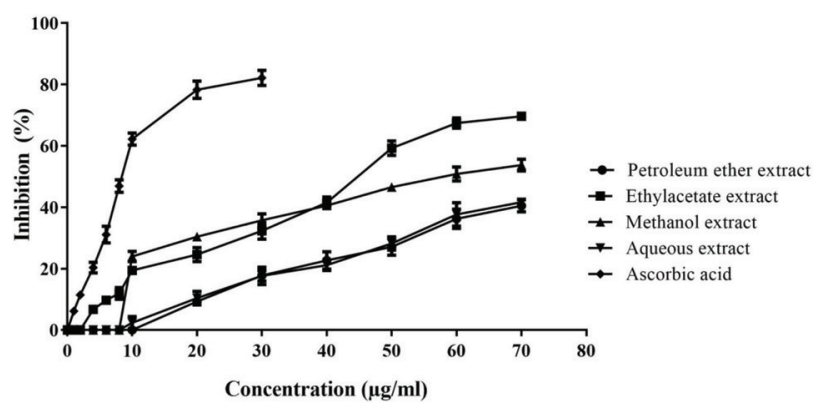

Figure 5: Nitric oxide inhibitory effects of extracts

\section{Acknowledgement}

Authors are thankful to Chitkara University Punjab for providing facilities for this research.

\section{Conflict of Interest}

There is no conflict of interest.

\section{References}

Ahmed, D., Khan, M.M., \& Saeed, R. (2015). Comparative analysis of phenolics, flavonoids, and antioxidant and 
antibacterial potential of methanolic, hexanic and aqueous extracts from Adiantum caudatum leaves. Antioxidants, 4(2), 394-409.

https://doi.org/10.3390/antiox4020394

Basu, S., \& Hazra, B. (2006). Evaluation of nitric oxide scavenging activity, in vitro and ex vivo, of selected medicinal plants traditionally used in inflammatory diseases. Phytotherapy Research, 20(10), 896-900. https://doi.org/10.1002/ptr.1971

Działo, M., Mierziak, J., Korzun, U., Preisner, M., Szopa, J., \& Kulma, A. (2016). The potential of plant phenolics in prevention and therapy of skin disorders. International Journal of Molecular Sciences, 17(2), 160. https://doi.org/10.3390/ijms17020160

Liguori, I., Russo, G., Curcio, F., Bulli, G., Aran, L., DellaMorte, D., Gargiulo , G., Testa, G., Cacciatore, F., Bonaduce, D., \& Abete, P. (2018). Oxidative stress, aging, and diseases. Clinical Interventions in Aging, 13, 757-772. https://doi.org/10.2147/CIA.S158513

Lubos, E., Handy, D.E., \& Loscalzo, J. (2008). Role of oxidative stress and nitric oxide in atherothrombosis. Frontiers in Bioscience, 13, 5323-5344.

https://doi.org/10.2741/3084

Pandey, K.B., \& Rizvi, S.I. (2009). Plant polyphenols as dietary antioxidants in human health and disease. Oxidative Medicine and Cellular Longevity, 2, 897484. https://doi.org/10.4161/oxim.2.5.9498

Pastorino, G., Cornara, L., Soares, S., Rodrigues, F., \& Oliveira, M.B.P.P. (2018). Liquorice (Glycyrrhiza glabra): A phytochemical and pharmacological review. Phytotherapy Research, 32(12), 2323-2339.

https://doi.org/10.1002/ptr.6178
Pizzino, G., Irrera, N., Cucinotta, M., Pallio, G., Mannino, F., Arcoraci, V., Squadrito, F., Altavilla, D., \& Bitto, A. (2017). Oxidative Stress: Harms and Benefits for Human Health. Oxidative Medicine and Cellular Longevity, 2017, 8416763. https://doi.org/10.1155/2017/8416763

Singh, V., Kahol, A., Singh, I.P., Saraf, I., \& Shri, R. (2016). Evaluation of anti-amnesic effect of extracts of selected Ocimum species using in-vitro and in-vivo models. Journal of Ethnopharmacology, 193, 490-499. https://doi.org/10.1016/j.jep.2016.10.026

Szymanska, R., Pospisil, P., \& Kruk, J. (2016). Plant-derived antioxidants in disease prevention. Oxidative Medicine and Cellular Longevity, 2016, 1920208. https://doi.org/10.1155/2016/1920208

Unuofin, J.O., \& Lebelo, S.L. (2020). Antioxidant effects and mechanisms of medicinal plants and their bioactive compounds for the prevention and treatment of type 2 diabetes: An updated review. Oxidative Medicine and Cellular Longevity, 2020, 1356893. https://doi.org/10.1155/2020/1356893

Uttara, B., Singh, A.V., Zamboni, P., \& Mahajan, R.T. (2009). Oxidative stress and neurodegenerative diseases: A review of upstream and downstream antioxidant therapeutic options. Current Neuropharmacology, 7(1), 65-74. https://doi.org/10.2174/157015909787602823

Veeresham, C. (2012). Natural products derived from plants as a source of drugs. Journal of Advanced Pharmaceutical Technology \& Research, 3(4), 200-201. https://doi.org/10.4103/2231-4040.104709 


\section{司}

\section{CHITKARA}

\section{Journal of Pharmaceutical Technology, Research and Management}

Chitkara University, Saraswati Kendra, SCO 160-161, Sector 9-C, Chandigarh, 160009, India

\section{Volume 8, Issue 1}

May 2020

ISSN 2321-2217

Copyright: [@2020 Varinder Singh and Amit Kumar] This is an Open Access article published in Journal of Pharmaceutical Technology, Research and Management (J. Pharm. Tech. Res. Management) by Chitkara University Publications. It is published with a Creative Commons Attribution- CC-BY 4.0 International License. This license permits unrestricted use, distribution, and reproduction in any medium, provided the original author and source are credited. 